\title{
Innovating Family Medicine Residency Education Through Collaboration
}

William F. Miser, MD, MA; Karen B. Mitchell, MD

(Fam Med. 2018;50(7):501-2.)

doi: 10.22454/FamMed.2018.462144

$\mathbf{S}$ teven Johnson, in his research of the greatest innovations during the past 700 years, concludes the majority were a result of collaborative efforts. ${ }^{1}$ In this issue of Family Medicine, Dr Carney et al summarize the outcomes of a 10-year study of transformation of a collaborative of 14 family medicine residency programs known as the Preparing the Personal Physician for Practice (P4) Project. ${ }^{2}$ They too emphasize the importance of collaboration in innovation. The work of this group has been impressive, with at least 39 papers published and over 150 national presentations given thus far. Their summary of findings and lessons learned is worthy of review by all program directors interested in innovating their residency programs.

Much has occurred in family medicine residency education since the initial 2004 Future of Family Medicine Report called for changes in the way we train our residents. ${ }^{3}$ The majority of family medicine residency programs are now considered patient-centered medical homes (PCMHs). New national advanced PCMH models such as the Comprehensive Primary Care Plus (CPC+) program of the Centers for Medicare and Medicaid Services (CMS) are being investigated as ways to strengthen and transform primary care. ${ }^{4}$ The Next Accreditation System of the Accreditation Council for Graduate Medical Education (ACGME) now encourages programs to be innovative in their approach to training, with flexibility granted around the "detail" requirements for programs that have met all "core" requirements with full continued accreditation.
Many of the items considered innovative in the $\mathrm{P} 4$ project are now considered essential by the ACGME Review Committee in Family Medicine (RC-FM). ${ }^{5}$ Access to an electronic health record (EHR) is a must, and today medical students universally receive training in an EHR. Residents are to learn leadership in team-based, interprofessional patient care, with an emphasis on patient safety and improved patient care quality. Training in population health has assumed more importance. Residency programs must be committed to the well-being of students, residents, faculty members, and all members of the health care team. This includes training residents to be resilient and adaptable.

Innovation and change come with a price. Organizational theory teaches us that change is naturally met with resistance, no matter how positive that change may be. If done too much and too fast, change fatigue can become a barrier. The P4 authors admit that some innovations come with a financial price tag that could be a barrier to implementation. Additionally, the complexity and amount of resources needed to create and study this large collaborative at the rigorous level described by the authors are daunting.

The authors make the case that "...every residency program should become part of a learning collaborative that works together to

From the Ohio State University Family Medicine Residency Program (Dr Miser); Association of Family Medicine Residency Directors (Drs Miser and Mitchell); and Ascension Providence Family Medicine Residency, Southfield, MI (Dr Mitchell). 
test and advance educational improvements." We embrace the concept of additional collaboratives. AFMRD supports the Family Medicine Length of Training Pilot that began in July 2013 with a goal of investigating whether extending the length of education in family medicine to 4 years of training in family medicine, through development of innovative education paradigms, further prepares family physicians to serve in a high-performance health care system. ${ }^{6}$ Seventeen programs, including both 4-year programs and 3-year control programs, are participating in data collection and yearly collaborative meetings. The pilot is funded by the American Board of Family Medicine Foundation (ABFM-F), and governed by the ACGME RC-FM with oversight by a Steering Committee of representatives from ABFM-F, RC-FM, and AFMRD.

In February 2018, the AFMRD and the UCSF Center for Excellence in Primary Care sponsored a collaborative of 18 family medicine residency programs interested in moving toward a "clinic first" residency paradigm. This paradigm emphasizes that primary care ambulatory resident education assumes equal or greater importance than inpatient residency education and that primary care residency teaching practices will strive toward more patient-centered care. Representatives from each of these 18 programs met for a face-toface meeting, with planned interactive videoconferences over the following year to share best practices in areas of data-driven improvement, empanelment, team-based care, access, continuity of care, resident scheduling, resident engagement, and resident wellness and satisfaction with their experiences in the office. Relevant metrics are being measured, with the intention to present the results at the 2019 AAFP Program Directors Workshop.

Another collaborative effort has spun off of the AFMRD Clinic First Collaborative. Some programs are being creative with resident rotation schedules to increase resident clinic experience, creating more compact times between clinic experiences and other rotational experiences. The result is that some programs may no longer meet the ABFM's requirement that each resident will have 40 weeks of continuity clinic experience per year. As a result, the AFMRD worked with the ABFM to facilitate a collaborative of 25 residency programs to study the impact of such scheduling on continuity of care, resident visit numbers, and resident wellness. This 5-year pilot is set to begin July
1, 2018 and may have an impact on future requirements for family medicine training.

The P4 program had the significant advantage of robust funding for evaluation of the project. This level of funding will rarely be available for other collaborative efforts. Nevertheless, tools are being developed collaboratively that are available for programs to use as they seek to incorporate evolving residency education content. When the ACGME placed increased emphasis on wellness within residency programs, AFMRD developed a task force to identify best wellness curricula for residency training. Likewise, as the recent opioid crisis gained national attention, the AFMRD responded to questions from the leadership of the American Academy of Family Physicians by collectively identifying best curricula for training residents in managing chronic pain and opioid prescribing. Both of these curricula are now housed in the AFMRD Toolbox for all to use.

We agree that every program should become part of a learning collaborative. The reality of funding dictates that some programs will have opportunities to participate in formal learning collaboratives with robust study results, while others will be able to use available tools and disseminate their experience with the tools. Collaboration makes us all better in educating residents as we seek continued improvement in the care we provide to our patients.

CORRESPONDING AUTHOR: Address correspondence to Dr Miser, 2231 N High Street, Columbus, OH 43201. miser.6@osu.edu.

\section{References}

1. Johnson S. Where Good Ideas Come From: The Natural History of Innovation. New York: Riverhead Books; 2011.

2. Carney P, Eiff MP, Waller E, Jones S, Green L. Redesigning residency training: Summary findings from the preparing the personal physician for practice (P4) project. Fam Med. 2018. 50;(7):503-17.

3. Martin JC, Avant RF, Bowman MA, et al; Future of Family Medicine Project Leadership Committee. The Future of Family Medicine: a collaborative project of the family medicine community. Ann Fam Med. 2004;2(suppl 1):S3-S32.

4. Centers for Medicare \& Medicaid Services Comprehensive Primary Care Plus. https://innovation.cms.gov/initiatives/ comprehensive-primary-care-plus. Accessed May 31, 2018.

5. Accreditation Council for Graduate Medical Education. ACGME Program Requirements for Graduate Medical Education in Family Medicine. https://www.acgme.org/Portals/0/PFAssets/ProgramRequirements/120_family_medicine_2017-07-01.pdf. Effective July 1, 2017. Accessed May 31, 2018.

6. Carek PJ. The length of training pilot: does anyone really know what time it takes? Fam Med. 2013;45(3):171-172. 